\title{
O DIREITO À CIDADE E O DESENVOLVIMENTO SUSTENTÁVEL URBANO: DILEMAS DO PLANEJAMENTO URBANO MODERNO
}

\section{THE RIGHT TO THE CITY AND SUSTAINABLE URBAN DEVELOPMENT: URBAN PLANNING DILEMMA MODERN}

\author{
${ }^{1}$ George Niclaides de Moraes Pires \\ ${ }^{2}$ Larissa Wegner Cezar
}

\section{RESUMO}

O presente artigo versa sobre os problemas ambientais gerados pela expansão desregrada das cidades. Tem como objetivo abordar o direito fundamental à cidade sustentável como um direito fundamental do homem. Para tanto será feita a observação do desenvolvimento das cidades a partir das práticas econômicas incentivadas pela modernidade, onde o liberalismo econômico permitiu facilmente a mercantilização dos espaços urbanos em desfavor do usufruto da coletividade. Posteriormente, analisar-se-á como a legislação contemporânea contemplou a regulação de alguns preceitos constitucionais neste sentido, a fim de garantir o fiel cumprimento das funções sociais das cidades e seus direitos respectivos.

Palavras-chave: Urbanização, Direito à Cidade, Planejamento Urano, Bem Comum, Desenvolvimento Sustentável.

\begin{abstract}
This article focuses on the environmental problems generated by the disorderly expansion of cities. It aims to address the fundamental right to sustainable city as a fundamental human right. For this will be the observation of the development of cities from economic practices encouraged by modernity, where economic liberalism easily allowed the commodification of urban areas to the detriment of the collective enjoyment. Later, it will be to examine how contemporary legislation contemplated the regulation of some constitutional provisions in this regard, to ensure the faithful fulfillment of the social functions of cities and their rights.
\end{abstract}

Keywords: Urbanization, Right to the City, Urban Planning, Common Good, Sustainable Development.

\footnotetext{
${ }^{1}$ Mestrando em direito pela Universidade de Caxias do Sul - UCS, Rio Grande do Sul (Brasil).

E-mail: george.moraespires@gmail.com

${ }^{2}$ Mestranda em Direito pela Universidade de Caxias do Sul - UCS, Rio Grande do Sul (Brasil).

E-mail: larissacezaradv@gmail.com
} 


\section{Introdução}

A partir da abordagem do tema relativo ao direito à cidade, várias são as questões que podem ser debatidas, envolvendo diversas temáticas, como a arquitetura, as ciências ambientais, a sociologia, e outras mais de grande relevância. A malha urbana acaba acontecendo no tempo e espaço, e seus desdobramentos envolvem e afetam diretamente a vida dos seus habitantes, tanto quando ocupam moradia quanto na necessidade de utilização de algum serviço inerente ao território.

Pode-se analisar neste trabalho, a necessidade de divagar pelos conceitos e condições estruturantes do direito à cidade nas cidades clássicas, partindo de análises feitas a partir de individualidades, influências religiosas, caráter coletivo dos interesses citadinos, até mesmo a forma de como a economia interferiu no relacionamento entre o Estado e os habitantes da urbe.

O processo de urbanização, principalmente no Brasil, se demonstrou desuniforme. A falta de atenção e de políticas públicas estatais permitiu que o desenvolvimento se desse de maneira desordenada, na medida em que a densidade demográfica se expandia em grandes proporções e o planejamento urbano era inexistente.

Quando realmente coube ao direito vincular-se aos interesses citadinos foi possível se verificar avanços no sentido de se tutelar anseios societários em relação ao território que se ocupava. Mas também coube ao direito permitir que, a partir do período pós-industrial, decorrente de conquistas jurídicas da modernidade, o excesso de individualismo e influências de interesses privados envolvessem a propriedade privada urbana a ponto de afastá-la de seu conceito original de bem de interesse coletivo.

A perda desse caráter coletivo e de bem comum relacionado à cidade, nada mais fez que massificar a prevalência dos interesses econômicos em face do atendimento do interesse da coletividade. Crescendo desordenadamente em decorrência da falta de planejamento urbano para todos, a parcela da população possuidora de poder econômico se permitiu adquirir a possibilidade de usufruir do meio ambiente urbano, quando a outra, à mercê das residuais políticas estatais, permanecia nas periferias e retratava o desatendimento do direito, fazendo morada em uma cidade "ilegal".

É diante disso que se aposta na real execução das diretrizes previstas no Estatuto das cidades, a partir da regulação dos preceitos consignados na Constituição Federal. A 
verdadeira função social das cidades só serão atendidas se medidas eficientes como a instrumentalização do direito à cidade, na forma do Plano Diretor por exemplo, forem colocadas em prática focando a essência coletiva do interesse de manutenção do equilíbrio sócio-ambiental do território urbano.

\section{Breve contextualização sobre os aspectos históricos e o processo de urbanização.}

As cidades nascem, na antiguidade, como uma necessidade do ser humano em conviver com os demais, como forma de proteger-se, de trabalhar para sua sobrevivência e seu bem-estar. A origem da ocupação urbana ocorreu a aproximadamente 5.500 anos (SJOBERG, 1970. p. 36).

No início as cidades eram tidas como uma fortaleza, transmitindo para as pessoas que nela habitavam a sensação de dignidade e segurança. Modernamente, há que se dizer que na sociedade, diante da marginalização e violência, hoje se vive em constante medo, verificase a necessidade de uma mudança no papel da cidade. Neste sentido Bauman que entende,

Os muros, os fossos, as paliçadas assinalavam o limiar entre "nós" e "eles", entre ordem e caos, paz e guerra: os inimigos eram mantidos do outro lado e não podiam se aproximar. Contudo, "depois de ter sido relativamente segura" nos últimos 100 anos a cidade se transformou em um lugar que faz pensar "mais no perigo que na segurança”.( BAUMAN, 2009. p. 61).

Seguindo este viés, no presente tópico faz-se uma breve análise histórica das cidades, objetivando verificar as mudanças ocorridas em seu território, sendo possível com essa abordagem, verificar a incidência danosa, causada pela progressiva expansão populacional das cidades, não só para os indivíduos, mas também ao meio ambiente natural.

A cidade, desde sua concepção, vem sendo uma contínua fonte de inovação, até mesmo em sua própria aparição, esta já acelerou fortemente a transformação social e cultural, onde se observa diversas formas de incentivo ao progresso, uma vez que muitas cidades foram concebidas em estradas importantes, facilitando o incentivo à inovação (SJOBERG, 1970. p. 43).

Os avanços dentro do espaço urbano implicam em um novo e acelerado rumo. Após a Revolução Industrial, com a divisão do trabalho, a invenção das maquinarias, e a consolidação da sociedade moderna, as cidades sofreram uma drástica mudança.

Dessa forma surgem as cidades industriais, Milton Santos caracteriza esses centros urbanos como cidades "construídas exclusivamente em função de uma fábrica ou de um 
conjunto delas, para alojar o pessoal empregado" (SANTOS, 1982. p. 102). As cidades tornam-se assim grandes pólos industriais, o que faz com que grande parte da população busque estes centros industriais a procura de trabalho, ocasionando um crescimento populacional urbano desordenado. A este processo chama-se urbanização (DOMINGUES, 2011. p. 75).

A cidade torna-se então um "objeto" do sistema capitalista para obtenção de lucro, resultando em uma força produtiva destinada a cumprir o objetivo monetário, pois com o aumento da população urbana, tem-se como consequência o aumento de mão de obra. Como nos esclarece Lefebvre,

\begin{abstract}
A cidade contém a população exigida pelo aparelho produtivo e "o exército de reserva" que a burguesia reclama para pesar sobre os salários tanto como para dispor de uma "rotatividade" de mão-de-obra. Mercado das mercadorias e do dinheiro (dos capitais), a cidade torna-se também o mercado do trabalho (da mão-de-obra) [...] A superpopulação latente, no campo como na cidade, é um dos fenômenos característicos do capitalismo [...] na cidade é deixada flutuante, segundo as necessidades da indústria, detida pelos capitalistas e gerida segundo suas exigências. (LEFEBVRE, 2001. p. 144).
\end{abstract}

Nota-se assim, que a superpopulação, é uma das formas de manutenção do sistema capitalista, uma vez que para conseguir suprir com a grande demanda da produção, imprescindível para obtenção do lucro e manutenção do sistema. Para o capital é necessário haver uma grande demanda de mão de obra, bem como, para que também o número de pessoas em espera seja maior do que o número de vagas de emprego, fazendo com que haja uma disputa por vagas e, possibilitando assim manter o baixo salário.

Vale salientar que este processo de superpopulação teve seu início anterior ao capitalismo, mas é após a consolidação das grandes indústrias, da burguesia e do capital que este processo de urbanização sofre uma aceleração, e anuncia a urbanização de grande parte da sociedade. Por meio dessa aceleração do crescimento populacional urbano, tem-se uma transformação radical no espaço territorial global e de toda a sociedade. (LEFEBVRE, 2001. p. 146).

No Brasil, este processo de urbanização tem como período de sua consolidação as primeiras décadas do século XX, em consequência da proclamação da República e do início da industrialização (MARICATO, 2001. p. 17).

Nas décadas de 80 e 90 pela primeira vez, e em números inéditos, o Brasil, tem uma abundância de pessoas centralizadas em algumas regiões, muitas delas, acometidas pela 
pobreza. Nesta época uma parte significativa dos brasileiros pobres concentravam-se nas metrópoles (MARICATO, 2001. p. 22).

Observa-se que as metrópoles tem um aumento ainda maior, depois da Segunda Guerra Mundial, tendo a incorporação de países recentemente industrializados ao sistema capitalista de produção, comércio e finanças. Com a organização da produção em fábricas de grande porte, como as automobilísticas, por exemplo. Esse modelo fez com que as pessoas fossem atraídas e se concentrassem em espaços territoriais limitados, havendo nesses locais uma grande quantidade de capital, trabalho, energia e consumo de recursos naturais (RATTNER, 2001. p. 12).

A partir dai verifica-se que a consolidação das metrópoles deu-se em decorrência da globalização, gerada por uma necessidade de expansão do sistema econômico vigente, pois com em função dessas, há uma "diminuição" das fronteiras, transformando algumas cidades em grandes centros globais. Neste sentido, Díaz assevera:

[...] este processo de urbanização experimentados pelos países latino-americanos está indubitavelmente ligado às grandes transformações econômico-territoriais que vêm ocorrendo de forma generalizada devido ao fenômeno global, pois precisamente um dos impactos gerados pela globalização econômica foi a formação de novas espacialidades. Assim, a formação e consolidação de grandes cidades e áreas metropolitanas obedeceu à dinâmica do capitalismo mundial, que as tornou territórios centrais em que se concentram as principais atividades econômicas, sociais, políticas e culturais. ( DÍAZ, 2005. p. 78).

Conforme, Blumenfeld, ao se referir sobre a migração da população para os grandes centros urbanos, pontua que

A migração do campo para a cidade permanece grande até hoje, mas agora existe, igualmente, uma forte onda de migração centrífuga, da cidade para os subúrbios. Embora em escala nacional a população esteja tornando-se cada vez mais urbana, está havendo dentro das cidades uma crescente descentralização. (BLUMENFELD, 1970. p. 55.)

Tem-se em evidência que as cidades brasileiras ainda passam pelo período de "explosão", ao que se refere a urbanização. Observa-se uma grande quantidade de pessoas migrando para as cidades-pólo a procura de emprego. Este aumento expressivo e imediato leva as cidades sem planejamento a enfrentarem problemas, acarretando a exclusão social. (MAHFUS, 2003. p. 75.)

Nota-se que acompanhando o fenômeno da urbanização em geral, tem-se a urbanização da pobreza, o que indica que há um grande processo de concentração de pobres nas áreas urbanas, muito, devido à evolução dos modelos econômico-produtivos. Fica 
evidente que este modelo é insuficiente e incapaz de interferir positivamente no desenvolvimento social. (DÍAZ, 2005. p. 79). Neste ponto, Young e Lustosa trazem que,

[...] o crescimento econômico acentuou ainda mais as disparidades de renda e riqueza entre as classes sociais na América Latina - as camadas mais abastadas da sociedade prosperaram mais que a maior parte da população, que possuía baixos rendimentos, sem a participação igualitária dos frutos do crescimento. (YOUNG; LUSTOSA, 2016. p. 207).

Destarte, esta parte da população excluída, em decorrência da não deter poder econômico, torna-se vulnerável as consequências que ocorrem no meio ambiente, por serem mais dependentes dos recursos ambientais, bem como por viverem em áreas desvalorizadas e, portanto áreas possivelmente degradadas ou mais expostas a desastres ambientais é o que denota Correa:

\begin{abstract}
Além das pessoas pobres serem mais dependentes dos serviços dos ecossistemas e, portanto, mais vulneráveis às mudanças que ocorrem nos mesmos, elas moram em zonas marginais com deficiente infra-estrutura física para a provisão da água potável, serviço de esgoto, tratamento de lixo e oferta de alimento. Ainda, os pobres dispõem de mínimos recursos financeiros para pagar água tratada e se obrigam a consumir águas diretas dos rios, mesmo estando contaminada. As pessoas pobres apresentam menores condições de habitação e se defrontam com maiores riscos de secas, inundações e outros eventos extremos. Os funcionamentos elementares das pessoas bem como os meios de subsistência podem estar ameaçados pelas más condições dos ecossistemas, por não dispor de algum tipo de planta medicinal, por reduzir a madeira utilizada para cozinhar e receber calor, por contar com água e ar contaminado, por reduzir espaços de recreação e gerar perdas de costumes e tradições. (CORREA, 2016. p. 6).
\end{abstract}

\title{
Continua a autora,
}

[...] considerando aspectos que tornam os pobres mais vulneráveis a mudanças que ocorrem no ambiente, como devido a sua maior sensibilidade, dada a dependência nos recursos naturais como meio de subsistência, no qual se destacam as pessoas do setor rural. De igual forma, as pessoas pobres são mais vulneráveis por estarem mais expostas a desastres climáticos como seca, inundações e tempestades, também por estarem em áreas mais degradadas e com limitado acesso a serviços públicos como água potável e saneamento básico. Estes últimos aspectos relacionados às restrições sociais e econômicas em que estão inseridas as pessoas pobres, que leva ao limitado acesso à educação, cuidados de saúde e precária infra-estrutura. (CORREA, 2016. p. 17-18).

A consequência do aumento das cidades, de sua ocupação sem qualquer regulamentação e a exclusão dos indivíduos detentores de menor capital do mercado imobiliário, pelo descaso, por parte do Estado em relação as habitações inapropriadas e clandestinas resulta na degradação do meio ambiente natural. Em vista disso, José Carlos sustenta que:

Dentre as principais consequências da extrema pobreza, que redunda na falta de alternativas de moradias legais (ou seja, reguladas pela legislação urbanística e inseridas na cidade oficial), está a agressão ambiental. 
A ocupação de áreas ambientalmente frágeis - beira dos córregos, encostas deslizantes, várzeas inundáveis, áreas de proteção dos mananciais - é a alternativa que sobra para os excluídos do mercado e dos insignificantes programas públicos.( SILVA, 2011. p. 234.)

Neste mesmo sentido, denota-se que a pobreza traz inúmeros problemas, sociais e ambientais, tais como a degradação ambiental, e salienta-se que com a modernidade estes problemas se intensificaram, e que com isso tem-se a perda da qualidade de vida da população nos espaços urbanos, Young e Lustosa esclarecem:

Assim, a industrialização não resolveu os problemas de pobreza e degradação ambiental nos espaços urbanos a princípio identificados com a "modernidade". Os grandes acidentes ambientais passam a se concentrar cada vez mais nas áreas metropolitanas, e a perda de qualidade de vida urbana (entendida em seu conceito mais amplo) torna-se uma das características mais marcantes das cidades brasileiras (e latino-americanas) no início do novo milênio. (YOUNG; LUSTOSA, 2016. p. 219).

Com isso, infere-se que através do processo de urbanização que se deu de forma desordenada, sem planejamento, tem-se a ineficiência do direito ao meio ambiente equilibrado, e ao desenvolvimento sustentável, tal fato será experimentados por todos, porém são os pobres que mais fortemente vivenciarão os danos e desastres ambientais pela falta de qualquer infraestrutura. É o que os autores acima citados mencionam,

[...] acelerado processo de urbanização e industrialização se deu sem a adequada infra-estrutura de serviços de saneamento, habitação, transporte etc. A deterioração das condições de vida nas periferias dos centros urbanos e outros locais de residência dos mais pobres pode ser vista, portanto, como a face ambiental do processo excludente de desenvolvimento: não apenas a renda e a riqueza se concentraram nas mãos das elites, mas também o direito a um ambiente saudável (como, de modo geral, o acesso a outras formas de bem-estar - segurança, educação, serviços de saúde). (YOUNG; LUSTOSA, 2016. p. 219.)

Assim, se percebe que o Estado mostra-se ineficiente e debilitado para conduzir de forma correta o desenvolvimento urbano, o que resulta em uma total condição de desproteção aos diferentes grupos sociais encontrados no ambiente urbano, bem como ao próprio ambiente natural e suas biodiversidades, onde nem mesmo os lugares já protegidos pelas normas ambientais são fiscalizados.

Nesse contexto, cabe a sociedade como um todo, criar uma forma para que sua interação com o meio natural se dê sem prejuízos a este. Desse modo, no que tange ao meio ambiente urbano sendo este um ambiente criado pelo homem dentro do espaço natural, deve ser pensado e planejado para interferir de forma menos danosa ao meio ambiente. 
Deve-se atentar-se na atual sociedade, para a problemática dos desastres ambientais, já experimentados no ambiente urbano em decorrência da ocupação inadequada do solo, como os deslizamentos, enchentes, entre outros.

Neste sentindo, faz-se necessário uma análise do planejamento urbano como instrumento capaz de efetivar o direito à cidade, necessário para a defesa e manutenção do ambiente natural, bem como a efetivação do desenvolvimento sustentável no espaço urbano, sendo este o tema do próximo tópico.

\section{$2 \mathrm{O}$ Direito à cidade no ordenamento jurídico brasileiro}

Nada mais atual nas discussões jurídicas e sociológicas contemporaneamente do que o tema direito urbanístico, tanto relacionando o tema do direito com discussões ambientais, tanto o vinculando a assuntos relacionados à economia. $\mathrm{O}$ direito à cidade vem com força nas pautas das reivindicações sociais, visto a realização do referido se encontrar vinculada a políticas públicas estatais que na maioria das vezes são aplicadas ao prazer de interesses privados.

Considerando que as relações sociais oriundas do aglomerado urbano vem sendo constantemente associadas à pratica econômica estatal, não há como se desvincular o comportamento do integrante da urbe ao excesso de consumo que o modelo atual vem pregando. As relações sociais contemporâneas são basicamente criadas a partir de ações vinculadas ao consumo.

Pode-se encontrar no decorrer da história diversos períodos onde as cidades puderam se predeterminar, tanto em sentido de otimização e busca da realização de um direito à cidade efetivamente exercido pelos seus habitantes quanto por períodos onde a realização desse direito ficou vinculada a práticas econômicas, como é o caso do período pós-industrialização.

As cidades e seus mais variados desdobramentos foram passíveis de estudo pelas mais diversas áreas do conhecimento. Do inicio de estudos pela arquitetura, sociologia e pelo direito, a partir da modernidade as cidades passaram a ser alvo de estudos a partir da temática verde do meio ambiente.

A modernidade passou a permitir transformações drásticas na forma de o direito à cidade se realizar, ou como pudera ser entendido. Isso porque, com o passar dos tempos, as conquistas permitidas pela modernidade jurídica relacionadas à propriedade privada foram 
incisivas na forma como as cidades passaram a se colocar no espaço. As próprias inovações legislativas permitiram que interesses particulares ou privados passassem a se impor ou prevalecessem em detrimento de interesses comuns ou coletivos.

As práticas econômicas atuais demonstram como as cidades foram vítimas da possibilidade de obter lucro pelas grandes corporações. O espaço urbano tornou-se centro de consumo, e isso permitiu que o direito à cidade fosse alcançado por somente uma das classes urbanas: a que detinha poder econômico pra comprá-lo. Isso apenas demonstra que efetivamente na contemporaneidade o direito à cidade só existe para as camadas mais abastadas das cidades, no sentido de que a mercantilização do meio urbano somente permitiu a segregação espacial e afastamento dos miseráveis para fora dos limites da cidade contemporânea, que para muitos doutrinadores é conhecida por "cidade legal".

$\mathrm{O}$ direito à cidade que se prega neste artigo é aquele oriundo da essência extraída pelos retratos das cidades clássicas, estudadas por Coulanges (COULANGES, 2004.) e Mumnford (MUMFORD, 1998. [1961].), ou do direito à cidade estudado por Lefebvre (LEFEBVRE, 2001). Modelos de cidade clássicas as quais foram alicerçadas em um bem maior ao praticado individualmente, de interesses meramente privados ou dissonantes dos interesses coletivos.

O direito à cidade foi visto por diversos ângulos pelos autores mencionados, mas pôde caminhar pelo no mesmo destino quando se consignou que o direito à cidade é oriundo da tutela de um bem maior, de um direito comum e condizente com os anseios da coletividade. A mobilidade urbana, direito à saúde, o direito à educação, o direito à participação política e até mesmo a prática de direito de modalidades mais complicadas como as liberdades democráticas, tais como liberdade de expressão, manifestação, locomoção e utilização do espaço público, são componentes de um direito à cidade.

Estes últimos direitos ficaram em evidência nas últimas manifestações populares, no ano de 2013, onde atos decorrentes de cidadania ficaram mais do que explícitos que visavam o atendimento do direito à cidade (ALFONSIN, 2015. p.25). Isso foi o estopim para que a população percebesse que tais direitos fossem de caráter essencial, desvinculados de qualquer condição social ou financeira da população.

Apesar de serem vistos de maneira separada, fragmentada, tais direito compõem um direito maior: o direito à cidade. O Estatuto da Cidade, Lei 10.257/01, introduziu no ordenamento jurídico brasileiro esse direito, agora consignando em seu texto a convicção de 
ser ele um interesse coletivo. Isso porque a menção feita pela Carta Constitucional de 1988, no artigo 182, de capítulo intitulado "Da ordem econômica e Financeira", somente mencionou que "A política de desenvolvimento urbano, executada pelo Poder Público municipal, conforme diretrizes gerais fixadas em lei, tem por objetivo ordenar o pleno desenvolvimento das funções sociais da cidade e garantir o bem-estar de seus habitantes." (BRASIL, CONSTITUIÇÃO FEDERAL, 2016).

Neste sentido, a partir da disposição constitucional mencionada, Bethânia Alfonsin interpreta o grande passo jurídico que se pôde dar em relação ao tratamento das cidades pelo ordenamento jurídico brasileiro, da seguinte maneira:

“O art. 182 da Constituição Federal, além de delegar a execução da política de desenvolvimento urbano aos entes municipais, mencionou a primeira vez na história do país as "funções sociais da cidade" como o objetivo da política urbana. O principio da função social da propriedade tem previsão constitucional desde a Carta Magna de 1934 todavia, ao incluir a expressão "funções sociais da cidade", o constituinte de 1988 além de ter demandado um esforço doutrinário de definição do sentido e do alcance dessa expressão, obviamente deu um salto de escala do bem individual "lote" (cuja propriedade também deverá atender a sua função social) para o bem coletivo "cidade", que, como totalidade, também deverá ser capaz de atender as suas funções sociais. A constituição de 1988, portanto, rompe com uma visão de "urbanismo lote a lote", de responsabilidade do proprietário, para pensar a cidade como um todo, demonstrando a intenção de fazer com que o país passasse a tratar o urbanismo como uma função pública e a própria cidade a ser tratada como um bem coletivo." (ALFONSIN, 2012. p. 323).

Como afirmado anteriormente, a promulgação do Estatuto da Cidade permitiu que o termo "direito à cidade" fosse incluso de maneira inédita em meio aos diplomas pátrios. A Constituição Federal apenas o vinculava a existência de uma função social do território urbano, oriundo do cumprimento dos preceitos previstos no Capitulo "Da Política Urbana", não determinando tratamento exclusivo ao termo.

Não há que se falar também em possível conceituação do direito à cidade dentro do ordenamento jurídico pátrio, mesmo que o artigo $2^{\mathrm{a}}$ do Estatuto da Cidade consigne algumas diretrizes, nada mais ali se determinou do que as funções sociais das cidades novamente, que viera ao mundo jurídico para regulamentar o que dispunha o dispositivo constitucional anteriormente mencionado.

“Art. 2ํ A política urbana tem por objetivo ordenar o pleno desenvolvimento das funções sociais da cidade e da propriedade urbana, mediante as seguintes diretrizes gerais:

I - garantia do direito a cidades sustentáveis, entendido como o direito à terra urbana, à moradia, ao saneamento ambiental, à infra-estrutura urbana, ao transporte e aos serviços públicos, ao trabalho e ao lazer, para as presentes e futuras gerações;" (BRASIL, ESTATUTO DA CIDADE, 2016.) 
Haja vista todas as formas como o direito à cidade vem sendo estudado contemporaneamente, não pode se deixar de ressaltar o resgate jurídico que se busca na readequação às formas de como fora tratado pelas cidades clássicas. A desfragmentação do direito em tela é necessária, no sentido de que o bem a ser tutelado é indivisível, é único, onde o atendimento por partes e aplicado em separado prejudicará e desvirtuará a verdadeira essência do direito à cidade.

É como um feixe de direitos que as cidades poderão realizar os anseios de bem-estar de seus habitantes. O processo de movimentação social mencionado anteriormente deixou nítido que a segregação espacial ocasionada pela prática do atual modelo econômico, o qual enseja o consumo exacerbado, prejudica a possibilidade de atendimento eficaz do direito à cidade.

Para além do previsto legalmente, esse feixe de direitos pode também compreender ainda mais garantias nesse direito coletivo à cidade, conforme consigna Bethânia Alfonsin, quando expõe que "o direito à cidade envolveria também o direito à gestão democrática, o direito de poder participar dos processos de tomada de decisões sobre a cidade, o direito da coletividade à recuperação da valorização imobiliária decorrente de investimentos públicos e, inclusive, o direito a um planejamento urbano que conduza a uma ordem urbanística inclusiva e sustentável às cidades brasileiras.” (ALFONSIN, 2015. p.26).

Isso tudo passa pela adaptação e reequilíbrio das instituições democráticas a partir do que a sociedade vem buscando quando grita pelo direito à cidade. Incumbe demonstrar também que não há mecanismos no ordenamento capazes de permitir a demanda coletiva pelo direito em tela, na medida que foram priorizados pela modernidade aqueles instrumentos que atendem o interesse particular ou privado, bem como a aplicação de políticas estatais que são endereçadas a pequenas parcelas da sociedade, quando relacionados ao interesse econômico.

A partir disto, necessária a análise de qual a forma para implementação deste direito à cidade, bem como, demonstrar como através dele estará se implementando a sustentabilidade no espaço urbano, tema do próximo tópico. 


\section{A efetivação do Direito à Cidade a partir do planejamento urbano ordenado e os desafios do desenvolvimento sustentável no espaço urbano}

O modelo econômico neoliberal praticado de maneira exacerbada, onde nitidamente esquece seus preceitos básicos e conceituais, adjudica nada mais que o enfraquecimento do Estado quando incumbido de cuidar dos interesses da coletividade. O aparato estatal é identificado como ineficiente quando se deixa atingir pelos interesses do capitalismo atual, onde permite a ação da pequena parcela da população detentora do capital influenciando na emissão de políticas públicas, que desvirtuam o real anseio dos habitantes das cidades.

Diante dessas afirmações, onde todas as práticas econômicas apontam pra um aumento de consumo e de lucratividade, consequentemente, o "neoliberalismo" vêm por massificar a ideia de que os detentores do capital exercem uma relação de superioridade hierárquica com os demais. Chomski retratou essa prática exagerada do capitalismo em face do abuso do "livre mercado" com a instituição do que chamou de "tiranias privadas" (CHOMSKY, 2002. p. 71).

A ideia de desfazer toda essa aplicação mercantil em desfavor das cidades é um dos anseios da pós-modernidade jurídica, mediante a reaplicação de conceitos de coletividade aplicados ao bem comum "cidade", que passam pela retirada de privilégios do habitante quando visto de maneira individual. A o atendimento do todo que se visa, mesmo ainda sendo claro na malha urbana a segregação espaço-temporal das classes sociais decorrente do mercado e da especulação imobiliária (PIRES, 2016. p.102).

O remédio para tudo isso passa pela possibilidade de tentar prever como a problemática atual poderá ser sanada a médio ou curto prazo, atreves do planejamento urbano. A longo prazo a elaboração de planejamentos relacionados ao desenvolvimento sustentável das cidades logicamente receberão benefícios. Pode-se alicerçar no planejamento Urbano as esperanças de que ele seja uma medida estimuladora na resolução dos problemas pelos quais a sociedade atual sofre.

O direito à cidade atualmente pode ser considerado aquele decorrente dos preceitos constitucionais previstos na $\mathrm{CF} / 88$, artigo 182 , mais precisamente na analise sistêmica de seus princípios visto não ser possível vislumbrar um conceito explícito no texto constitucional. Ali se consigna o direito que terá o habitante das cidades de poder usufruir do espaço urbano de maneira ambientalmente sustentável. Como relatou anteriormente Alfonsin (ALFONSIN, 
2011. p.36.) o termo "direito à cidade" só foi incluso no ordenamento jurídico brasileiro a partir da promulgação do Estatuto da Cidade (ALFONSIN, 2011. p.36).

É através do Estatuto das cidades que diversos mecanismos ou instrumentos foram instituídos com a finalidade de permitir a aplicação de um verdadeiro direito à cidade. Mesmo ainda sem aprofundar o tema no tocante a verdadeira efetividade dos dispositivos ali elencados, Alfonsin pensou que "para os territórios urbanos, pela primeira vez, é dispensado um tratamento específico e prenhe de promessas de correção das graves distorções do processo de urbanização de nosso país." (ALFONSIN, 2001. p.310).

Por outro lado, pode-se considerar que muito pouco se evoluiu em relação ao assunto no Brasil. Para Rech, o território urbano "legal” ainda não foi alcançado da forma como deveria pelo ordenamento jurídico brasileiro, mesmo após a promulgação do Estatuto das Cidades, pois as instituições democráticas de direito demonstram a inabilidade para aplicar os atuais conceitos, consequentemente falindo as intenções do diploma mencionado (RECH; RECH, 2010. p.31).

Tem-se utilizado o instrumento do plano diretor, previsto no Estatuto da cidade, como instrumento hábil de permitir o estabelecimento de maiores diretrizes no planejamento urbano municipal. O desenvolvimento visto nas cidades dos últimos anos apresenta a real e urgente necessidade de utilização de planejamento aplicado ao território citadino. O que se vê é o drástico e desordenado desdobramento da malha urbana em favor de interesses econômicos e à mercê de interesses alheios aos da coletividade e aos de interesse do bem comum.

As predeterminações jus-urbanísticas das instituições municipais obviamente também são orientadas pelos preceitos do artigo 182, § $2^{\circ}$ da Constituição Federal, e por isso utilizam regulações previstas no Estatuto para a aplicação do Plano diretor municipal. Isso quer dizer que esse mecanismo legal deve ser orientado e fundamentado no direito fundamental a uma cidade sustentável, respeitando os princípios previstos na referida carta constitucional, de gestão democrática, justiça social, função social da propriedade/cidade, sustentabilidade urbana e ambiental e, por consequência destes todos, obediência ao princípio da dignidade da pessoa humana, onde sua não observância pode levá-lo ao fracasso e falta de embasamento constitucional (PINHEIRO; RODRIGUES, 2011/2012. p.384).

Em suma, vale explicitar que a realização de um direito à cidade passa pelo reconhecimento das instituições democráticas de direito do fato de que o direito em tela é um 
direito fundamental da pessoa humana, bem como é resultante da existência de um feixe de direitos, onde o atendimento eficaz só será possível de maneira única e indivisível. Para melhor atendê-lo existe a necessidade de ações dos poderes pertinentes no tocante a se antever e proporcionar ações de planejamento urbano a fim de sanar com a problemática no decorrer do tempo, já que isso ainda perduraria por algum período. Na máxima de que quanto antes isso ocorrer, antes veremos os resultados do que se planejou anteriormente, o direito à cidade vem tentando deixar de ser híbrido, para que com o tempo torne-se algo concreto no ordenamento e por fim, realizável de fato para os moradores urbanos.

A concretização do direito à cidade através do planejamento urbanos é um importante avanço para a efetivação do princípio do desenvolvimento sustentável no espaço urbano, até porque o próprio Estatuto da Cidade, traz como diretriz, entre outros, a garantia do direito à cidades sustentáveis e como instrumento, dentre outros, para o planejamento urbano atender tal diretriz.

Referindo-se ao princípio do desenvolvimento sustentável, encontra-se na Constituição de 1988, seu conceito é bastante complexo e ainda não definido na doutrina, embora seja quase pacífico que envolve as seguintes dimensões: ambiental, social, econômica e temporal dos processos urbanos. E segundo a Comissão Mundial sobre Meio Ambiente e Desenvolvimento da ONU, conhecida como Comissão Brundtland, "desenvolvimento sustentável é aquele que atende às necessidades do presente sem comprometer a possibilidade de as gerações futuras atenderem as suas próprias necessidades" (PENNA, 1999. p. 140).

A partir dos debates desta comissão, o desenvolvimento sustentável tornou-se muito mais conhecido e discutido, passa a ser tratado como uma possível solução para alcançar o equilíbrio ecológico.

O princípio do desenvolvimento sustentável surge com o objetivo de sanar os conflitos entre o desenvolvimento econômico e a preservação ambiental. $\mathrm{O}$ alcance deste princípio é um dos objetivos da Política Nacional do Meio Ambiente (Art.4 ${ }^{\circ}$, I, Lei $\mathrm{n}^{\circ}$ 6.938/81). Sirvinskas esclarece que este princípio também poderia ser denominado como princípio da ordem econômica, devido ao fato de que as atividades econômicas são as maiores causadoras da degradação do meio ambiente (SIRVINSKAS, 2008. p. 184).

Para que haja possibilidade de alcançar o desenvolvimento sustentável, é necessária uma utilização controlada dos recursos naturais, uma mudança no modo de vida da sociedade, é necessária a conscientização ecológica de cada indivíduo. 
O termo sustentabilidade ambiental está intrinsecamente ligado a sociedade sustentável, abrangendo a perspectiva de um mundo ambientalmente sadio, tendo que se falar em uma cooperação global.

A crise ambiental coloca a necessidade de dar bases de sustentabilidade ao processo econômico, procurando controlar e reverter os custos ecológicos dos padrões de produção e consumo, e seus efeitos na deterioração ambiental e na qualidade de vida das maiorias. (LEFF, 2006. p. 406.)

A sustentabilidade enseja que as carências sociais sejam sanadas pelo aumento da produção e pelo estabelecimento de oportunidades políticas, econômicas e sociais, que sejam iguais para todos. A atmosfera, a água, o solo e os ecossistemas, que são fundamentais à vida na Terra, não podem ser postos em riscos pelo desenvolvimento (PENNA, 1999.p. 140).

Ainda, necessário se faz distinguir tal principio da economia verde, que surgiu nos debates ambientais nos últimos anos como alternativa para garantia do bem ambiental. A economia verde é na verdade um meio para se alcançar o desenvolvimento sustentável. O Programa das Nações Unidas para o Meio Ambiente (Pnuma), lançada em 2008, concebe a Economia Verde como

aquela que resulta em melhoria do bem-estar humano e da igualdade social, ao mesmo tempo em que reduz significativamente os riscos ambientais e a escassez ecológica. Ela tem três características preponderantes: é pouco intensiva em carbono, eficiente no uso de recursos naturais e socialmente inclusiva (PNUMA. 2016).

A ideia central desse termo, portanto, é de que o conjunto de processos produtivos da sociedade e as transações deles decorrentes contribuam cada vez mais para o desenvolvimento sustentável, tanto nos aspectos sociais quanto ambientais. A economia verde propõe que, além das tecnologias produtivas e sociais, sejam criados meios pelos quais fatores essenciais ligados à sustentabilidade socioambiental, hoje ignorada nas decisões econômicas, passem a ser considerados.

Uma das críticas que se faz a economia verde, é de que ela pode ser utilizada como publicidade apenas para vender produtos e ideias com o "selo verde" com o intuito apenas econômico. O autor Sawier menciona nesta seara o seguinte,

A economia verde, por outro lado, poderá não passar do acréscimo superficial de alguns setores ou camadas adicionais. Pode se resumir a atividades ou projetos verdes atualmente na moda, tais como painéis fotovoltaicos, moinhos eólicos, parques nacionais remotos, pontos de reciclagem de lixo, hortas orgânicas e pousadas ecoturísticas na selva, sem mudar o principal, que são os padrões de produção e consumo insustentáveis. A economia verde facilmente acaba se tornado lavagem verde cosmética (greenwashing) (SAWYER, 2016.p.37). 
Portanto, deve-se tomar cautela com relação a economia verde para que ela não seja utilizada como uma maneira de gerar lucro. Quanto ao princípio da sustentabilidade, denotase que este está intrinsecamente ligado ao princípio da equidade intergeracional, pois para haver a sustentabilidade é necessário que os recursos naturais sejam distribuídos de forma equitativa, pois os bens ambientais são de todos e devem ser cuidados de forma racional.

Conforme o caput do art. 225 da CF, "impondo-se ao Poder Público e à coletividade o dever de defendê-lo e preservá-lo para as presentes e futuras gerações”, cabe as presentes gerações usar dos recursos naturais de forma racional e moderada para não deixarem para as futuras gerações uma quantidade negativa de recursos, é disto que trata o princípio da equidade intergeracional.

A partir deste princípio tem-se a ideia de que a sociedade deve distribuir igualmente os benefícios e os malefícios, advindos desta, entre todos. Este princípio tem como elemento principal a solidariedade.

Não existe nenhum fundamento para a que presente geração tenha preferência em relação às futuras gerações. Ações isoladas não são a solução para o problema ambiental, pois este somente será resolvido através de uma cooperação global. O princípio do acesso equitativo encontra-se no princípio 3 da Declaração do Rio de Janeiro: "O direito ao desenvolvimento deve ser exercido de modo a permitir que sejam atendimento equitativamente as necessidades de desenvolvimento e de meio ambiente das gerações presentes e futuras" (SAMPAIO, 2003. p. 57).

Conforme Leff, "para alcançar os objetivos da sustentabilidade e da equidade, será necessário desconstruir a racionalidade econômica e construir uma racionalidade ambiental" (LEFF, 2006.p. 154).

Assim, o planejamento urbano, junto com os demais instrumentos jurídicos previstos na legislação, que levará a garantia do direito à cidade, é capaz de fazer com que a sustentabilidade ambiental seja alcançado no espaço urbano, pois . O que importa são as necessidades do planeta e das futuras gerações, que dependem da manutenção de funções ecossistêmicas, com ou sem recursos adicionais, novas tecnologias e novas formas de governança global. Com isso, afirma-se que a saída para uma sociedade mais justa exige, além de redistribuição de renda e riqueza, a modificação nos padrões de consumo, onde o 
interesse coletivo volte a ser privilegiado sobre o individual, e que a inserção do excluído seja por sua cidadania, e não pelo seu poder aquisitivo.

\section{Considerações Finais.}

A partir do momento que se dá o crescimento desregrado da população urbana e as cidades mostram-se incapaz de acolher e oferecer estrutura para o grande número de habitantes tem-se o problema da exclusão social e da consequente degradação ambiental.

A ideologia econômica é que rege o desenvolvimento urbano, transformando a cidade em uma mercadoria a ser consumida.

A proteção ambiental, nesse contexto, é deixada de lado. Verifica-se uma total condição de desproteção ao ambiente natural e sua biodiversidade, onde as normas regulamentadoras urbanas e ambientais, somente são efetivadas em ambientes relevantes economicamente. Segue-se, portanto os preceitos da economia capitalista de mercado, não se levando em conta o transtorno ambiental que se vive, como consequência de um desenvolvimento urbano irresponsável, despreocupado e desprendido do meio natural. Tais características já deixaram, ao longo dos anos, perdas irreparáveis no meio ambiente e tais perdas tentem a continuar ocorrendo enquanto tomarem-se atitudes irracionais que levem em conta apenas os interesses econômicos.

Portanto, remata-se com o ideal de que haja uma mudança no comportamento dos indivíduos, das comunidades e da sociedade, em cobrar do Estado a efetivação das normas vigentes, para que se efetive o planejamento urbano levando-se em conta os interesses econômicos, e também os interesses ambientais e sociais, efetivando a sustentabilidade no espaço urano. A proteção do meio natural é responsabilidade que cabe a todos, caso ainda seja o desejo que exista vida humana no planeta Terra.

Isso quer dizer que a saída para uma sociedade mais justa exige, além de redistribuição de renda e riqueza, a modificação nos padrões de consumo, onde o interesse coletivo volte a ser privilegiado sobre o individual, e que a inserção do excluído seja por sua cidadania, e não pelo seu poder aquisitivo. O objetivo fundamental não é meramente o crescimento econômico, mas o desenvolvimento sustentável. 


\section{Referências Bibliográficas.}

ALFONSIN, B.M. Direito à cidade sustentável na nova ordem jurídico-urbanistica brasileira: emergência, internacionalização e efetividade em uma perspectiva multicultural. In: Antonio Carlos Wolkmer; José Rubens Morato Leite. (orgs.). Os novos direitos no Brasil: natureza e perspectivas, uma visão básica das novas conflituosidades jurídicas. $1^{a} E d$. São Paulo: Saraiva, 2012.

ALFONSIN, Bethânia. Quando o direito à cidade entra em cena. In: Urbanismo, Planejamento Urbano e Direito Urbanístico: caminhos legais para cidades sustentáveis. Editora e Gráfica Cenecista Dr. José Ferreira: Uberaba, 2015.

BAUMAN, Zygmunt. Confiança e medo na cidade. Rio de Janeiro: Jorge Zahar, 2009.

BLUMENFELD, Hans. A metrópole moderna. In: Cidades: a urbanização da humanidade. Rio de Janeiro: Zahar editores, 1970.

BRASIL. Constituição Federal. Artigo 182, caput. Disponível em: Acesso em: 30 de Agosto de 2016.

BRASIL. Estatuto da Cidade. Lei nº10.257, de 10 de Julho de 2001. Regulamenta os arts. 182 e 183 da Constituição Federal, estabelece diretrizes gerais da política urbana e dá outras providências. Acesso em 30 de Agosto de 2016.

CHOMSKY, Noam. O Lucro ou as Pessoas. Brasil: Bertrand Editora, 2002.

CORREA, Esmeralda. QUAL A RELAÇÃO ENTRE POBREZA E MEIO AMBIENTE? Evidências e Reflexões desde uma Perspectiva Multidimensional do Bemestar Humano. Disponível em: www.pucrs.br/eventos/alcadeca/download/pobreza-e-meioambiente.doc. Acesso em: 20 de julho de 2016.

COULANGES, Fustel. A cidade antiga. Rio de Janeiro: Ediouro, 2004.

DÍAZ, Laura Mota. As faces atuais da pobreza urbana: elementos para uma reorientação da política social. In: DÍAZ, Laura Mota; CATTANI, Antonio David. Desigualdades na América Latina: novas perspectivas analíticas. Porto Alegre: Editora UFRGS, 2005.

DOMINGUES, Rafael Augusto Silva. Competência constitucional em matéria de urbanismo. In: DALLARI, Adilson Abreu; DI SARNO, Daniela Campos Libório. Direito urbanístico e ambiental. Belo Horizonte: Fórum, 2011.

JUNIOR, Amandino Teixeira Nunes. O Estado Ambiental de Direito. Brasília, 2004.

LEFEBVRE, Henri. A cidade do capital. Rio de Janeiro: DP\&A, 2001.

LEFF, Enrique. Ecologia, Capital e Cultura: A territorialização da racionalidade ambiental. Rio de Janeiro: Vozes, 2009. 
MAHFUS, Julio Cesar. Gestão pública democrática e o estatuto da cidade. Cachoeira do Sul: Gráfica Jacuí, 2003.

MARICATO, Ermínia. Brasil, Cidades: alternativas para a crise urbana. Petrópolis: Vozes, 2001.

MUMFORD, Lewis. A cidade na história. São Paulo: Martins Fontes, 1998. [1961].

PENNA, Carlos Gabaglia. O Estado do Planeta: Sociedade de consumo e degradação ambiental. Rio de Janeiro: Record, 1999.

PINHEIRO, Gabriele Araújo Pinheiro. RODRIGUES, Wagner de Oliveira. Direito fundamental à cidade sustentável e os dilemas do planejamento urbano no estado democrático de direito. Revista Faculdade de Direito da Universidade de São Paulo. Volume 106/107, p. 373 - 387: Jan/dez. 2011/2012.

PIRES, George N.M. SANTOS, Sandrine A. Função social da cidade, risco ambiental e resiliência urbana social. In. Função socioambiental da propriedade [recurso eletrônico] / organizadora Marcia Andrea Bühring. - Caxias do Sul, RS : Educs, 2016.

PNUMA. Disponível em: http://web.unep.org/regions/brazil/other/efici\%C3\%AAncia-derecursos Acesso em 23 de julho de 2016.

RATTNER, Henrique. Prefácio. In: ACSELRAD, Henri. A duração das cidades: sustentabilidade e risco nas políticas urbanas. Rio de Janeiro: DP\&A, 2001.

RECH, Adir Ubaldo. RECH, Adivandro. Direito Urbanístico: fundamentos para a construção de um plano diretor sustentável na área urbana e rural. Caxias do Sul, RS: Educs, 2010.

SAMPAIO, José Adércio Leite; WOLD, Chris; NARDY, Afrânio. Princípios de direito ambiental: na dimensão internacional e comparada. Belo Horizonte: Del Rey, 2003.

SANTOS, Milton. A urbanização desigual: Especificidade do fenômeno urbano em países subdesenvolvidos. Petrópolis: Vozes, 1982.

SAWYER, Donald. Economia verde e/ou desenvolvimento sustentável ? Política Ambiental / Conservação Internacional - n. 8, jun. 2011 - Belo Horizonte: Conservação Internacional, 2011. Disponível em: http://www.ie.ufrj.br/images/gema/Gema_Artigos/2011/PoliticaAmbiental08portugues.pdf . Acesso em: 21 de julho de 2016.

SILVA, José Carlos Alves da. Favelas e meio ambiente urbano. In: DALLARI, Adilson Abreu; DI SARNO, Daniela Campos Libório. Direito urbanístico e ambiental. Belo Horizonte: Fórum, 2011.

SIRVINSKAS, Luís Paulo. Tutela Constitucional do Meio Ambiente. São Paulo: Saraiva, 2008. 
SJOBERG, Gideon. Origem e evolução das cidades. In: Cidades: a urbanização da humanidade. Rio de Janeiro: Zahar editores, 1970.

YOUNG, Carlos Eduardo Frickmann; LUSTOSA, Maria Cecília Junqueira. A questão ambiental no esquema centro-periferia. ECONOMIA, Niterói (RJ), v.4, n. 2, p.201-221, jul./dez. 2003. Disponível em: http://www.anpec.org.br/revista/vol4/v4n2p201_221.pdf. Acesso em: 21 de julho de 2016. 